\title{
Forensic Analysis of Failing Software Projects Issues and Challenges
}

\author{
Stephen H. Kaisler, D.Sc. \\ SHK \& Associates \\ Laurel, MD 20723 \\ Skaisler1@,comcast.net
}

\author{
William H. Money, Ph.D. \\ Baker School of Business \\ The Citadel \\ Charleston, SC \\ wmoney@citadel.edu
}

\author{
Stephen Cohen \\ Chief Architect \\ Microsoft Corporation \\ Redmond, WA \\ Stephen.cohen@microsoft.com
}

\begin{abstract}
Software project failure has directly and indirectly cost trillions of dollars over the past fifty years. The reasons for failure are many. Recently, we began investigating methods for software project forensic analysis in order to develop principles and practices that would enable better understanding why, when, where, how, and what causes software project failure. This paper examines some of the issues and challenges in performing forensic analysis of failing or failed software projects. We propose an initial model based on this first analysis to assist in critically evaluating potential causes and assessing the potential for failure.
\end{abstract}

\section{Introduction}

The bad news is: Software Projects Fail! But there is good news! We can determine why they are failing/fail and we can specify methods to mitigate or recover from the failure state. The reasons software projects fail are well described. [1], [2], [3] Many experts and bloggers have enumerated the reasons for failure. Despite the many prescriptions for conducting successful software projects, such as Capers Jones publications, people find interesting ways to achieve failure or fail to deliver on the original promise for their software projects. As Capers Jones notes, 'There are many ways to make large software systems fail. There are only a few ways of making them succeed' [4]. Bryson and Bromily [5] identified potential project success factors and found that most successful projects had all of the success factors; and that the success factors are interrelated.

The process of mitigating and recovering from actual or pending software project failure has not been adequately analyzed and researched. This paper focuses on issues and challenges in recognizing, analyzing, and recovering from actual or impending failure in software projects. Our prescriptions are not guarantees, but suggest analysis, remediation, and recovery procedures that project managers can apply to back away from the precipice of failure and take positive action with the intent of delivering useful software to the target users.

One important Caveat: forensic analysis for failed software projects overlaps with digital forensics for cybersecurity, and may share some techniques. However, this research addresses the broader subject - the entire software development lifecycle and utilizes several variables absent from existing cybersecurity analytical frameworks.

\section{Motivation}

Why is it important to understand why software projects fail and how to recover from impending failure? Krigsman [6] has noted that the worldwide cost of software project failure is in the trillions of dollars. This is more than the GDP of all but a few nations. As large software projects become more prevalent, they become more costly due to the complex requirements, architecture, and design needed to meet their scale in a modern cloud-based world.

Determining why software projects are failing and then, applying remediation and recovery processes can mitigate the compounding effect of failing causes. We identify issues and challenges that directly address the causes of failure and reduce project risk. We believe it is a first step to assist project managers and researchers in understanding the mechanism for software project recovery.

One example of a massive software project that seemed to always teeter on the brink of failure was the Federal Aviation Administration's Advanced Automation System (AAS) [7]. This project, begun in 1981, was intended to provide a complete overhaul of the nation's major air traffic control computer systems. It would provide new tools and displays for controllers to improved communication equipment and a revamped core computer network to modernize U.S. airspace through new technology to make flying safer, 
more efficient, and more predictable. Numerous delays and challenges arose that caused FAA to revise its budget projections, functionality, and completion date over its lifetime until 1994 when it was canceled. Of $\$ 2.6$ billion spent less than half of the technology was usable in follow-on projects. This project was affected by many problems. Some of the problems, initially identified by GAO [7], necessitated AAS redesign several times. After this failure, the FAA began a new project - the Next Generation Project, with the same goals. It is composed of smaller projects, but seems prone to some of the same problems that affected the AAS.

\section{Technical Approach}

Our technical approach to providing guidance on research and application of recovery procedures will answer two research questions and provide an initial model for further research:

(1) What are some key issues and challenges for employing forensic analysis techniques to investigate failing software projects based on the current project failure literature; and

(2) What are some primary issues and challenges in attempting to recover from software project failure; and

(3) Propose an initial model to detect and assess causes of pending project failure.

This paper assumes that stakeholders (executives, managers, staff, etc.) recognize that a software project is failing or that failure appears imminent. Recognizing that a software project is failing and admitting that it is failing - to oneself, the development team, the stakeholders, and to the executive sponsors - is a critical step in recovery. Once this recognition of (impending) failure has been achieved (or perhaps admitted), the first step is to perform a forensic analysis of the software project to determine the HOW and the WHY it is failing.

To determine whether recovery is possible, must gather information and analyze it to discover why a project is failing or has failed. From this analysis, the team can determine whether (a) to attempt project recovery - partially or wholly, or (b) permit it to fail and decide whether or not to try again. This process also provides the opportunity to identify potential recovery procedures and examine the issues and challenges of applying them to effect project recovery.

The remainder of this paper is organized into five sections. Section 4 provides a definition of Forensic Analysis. Section 5 addresses our primary research questions. Section 6 presents our initial model for detecting and assessing potential causes of failure. Section 7 presents our conclusions and section 8 discusses future work.

\section{Forensic Analysis - A Definition}

Forensic Analysis is "the use of scientifically derived and proven methods to preserve, collect, validate, identify, analyze, interpret, and document the evidence derived from digital and other sources for the purpose of facilitating or furthering the reconstruction of events leading to the (impending) failure of a (software) project" [8].

We have coined the term "Project Autopsy" to mean the application of forensic analysis principles and procedures to determining the how and the why a project has failed. Analogous to medical autopsy, we looked to other fields such as law enforcement, forensic pathology, and military battle damage assessment for digital forensic methods to develop a framework for software project forensic analysis. This framework yielded questions that must be asked and data that must be gathered to discover processes, events and patterns of decision-making in software project management that lead to software project failure. This approach addresses a software project failure as an event that can (perhaps) be avoided and not as a foregone conclusion as a number of researchers have noted. [9] [10] [11]

A project can be in failure mode, but continue to operate (spend more, consume resources, revise plans and schedules, and produce reports). Without any recovery procedures being implemented, management will have to make a critical determination of future activities. Resource allocation decisions made in multi-project environments can be revised, and implemented as part of a broader strategy that may allow (intentionally or unintentionally) one project to fail thereby releasing needed resources to other projects [12]. This is similar to firefighters making the difficult but often necessary decision to allow one home to burn while focusing on saving the neighboring homes.

Many decisions, if detected during project execution, can signal a pending failure. These decisions do not necessarily occur at the beginning of a project, but can occur at any time during the project. A project that seems to be succeeding in the early stages, but then appears to enter a pending failure mode is best supported through periodic forensic analysis. This predictive element, which may not produce any result leading to a healthy, successful 
delivery, is an investment that should be made to detect pending failure as early as possible.

\section{Employing Forensic Analysis: Challenges}

Forensic analysis requires four essential tasks: (1) observe: gather as much of the relevant data about the project possible within reasonable time constraints; (2) measure: analyze the data to determine where problems arose and the impact of decisions contributing to failure, (3) plan an incremental approach allowing for feedback to drive adaptations over time and then (4) act on that plan. Throughout these tasks, the recovery team needs to provide continuous reporting on why a project is failing or in failure mode and formulating what can be done about it. The details of the final task, act, depend on a commitment by an organization's executive management that either the project is recoverable and actions will be taken to recover it or the project will be abandoned. We address the first three items in this paper. Cohen, Kaisler, and Money [8] addressed the last item in their HICSS-53 tutorial.

\subsection{Analytic Techniques}

Forensic analysis applies analytical processes to project data to understand why a project is failing or has failed. A large and enduring set of literature documents the many software projects that have ended in failures and the impacts of these outcomes. The literature suggests that there are many issues and challenges in performing forensic analysis on the projects. Many of the failures have yielded lessons learned through post-mortem analysis [13]. Many other software projects are failing now but could be in recovery if forensic analytic techniques were known and applied to them. [14] [15] [16]

The techniques that previously have been applied to analyze the state of a project (on a very basic success - failure continuum) are many. They include; system and outcome-based key performance indicators (KPIs), process and product quality metrics such as completeness and code quality (that lead to technical deficiency), human dynamics preventing team stress, communications blocks preventing clear messaging, and poor management practices such as failures to properly identify workloads and staff project activities [17]. It is noted that the techniques are not applied in total to any one software project although all may have some value and contribute to an understanding of the reasons for the failure.

\subsection{Observe the Causes}

To understand why a software project is failing or has failed, it is critical to understand the root causes of failure. Few failing/failed projects have a single cause. Rather, there may be many root causes, including the complexity of the project, its architecture, its management structure, and the critical skills possessed by multiple individuals on the project. Root causes may also have interdependencies in complex projects. Thus, root cause analysis is not a single method, but a suite of methods that one can choose from to identify and focus attention on root causes. Table 1 identifies some issues in causal analysis.

Table 1. Causal Analysis

\begin{tabular}{|c|}
\hline $\begin{array}{l}\text { Stakeholders: Are the stakeholders' goals, dynamics - } \\
\text { interpersonal and organizational, - and requirements } \\
\text { understood? Whose success is most critical (in rank } \\
\text { order)? }\end{array}$ \\
\hline $\begin{array}{l}\text { Dependencies: Is there a coherent model of } \\
\text { dependencies? For people? For technology? For business } \\
\text { processes? For required vs. optional data? [17] }\end{array}$ \\
\hline $\begin{array}{l}\text { Use of tools: What tools can be used to facilitate causal } \\
\text { analysis? Are they accessible to the analysis team? }\end{array}$ \\
\hline $\begin{array}{l}\text { Key Skills: What essential skills are required to conduct a } \\
\text { reliable forensic analysis that is defensible and } \\
\text { explainable? }\end{array}$ \\
\hline $\begin{array}{l}\text { Management: Does (did) the project leadership have the } \\
\text { right management skills - based on experience and } \\
\text { training - to conduct a successful project? }\end{array}$ \\
\hline $\begin{array}{l}\text { Technology: Did the development team(s) have the right } \\
\text { knowledge, training, and experience to execute the } \\
\text { project? }\end{array}$ \\
\hline
\end{tabular}

Like other domains, forensic analysis of failing software projects requires specialized skills beyond routine analysis and design skills. A current challenge is to identify and describe those skills and develop the educational and training programs to create a cadre of forensic analysts.

In other domains, forensic analysis is performed by a third party or independent internal team not previously associated with the project. This team performs the three essential tasks of forensic analysis. If the management decision is to conduct recovery operations, an assessment of the development team is necessary to determine if they can perform a recovery operation.

An apparent reason for the failure of AAS as cited by the GAO [7] was the lack of "adequate oversight" of IBM's performance on development activities. The FAA did not appear to have appropriate project management expertise for a project of AAS's magnitude and complexity. 


\subsection{Measure and Assess Causes and Effects}

It is essential to identify where impediments exist within a project or the organization sponsoring the project that are preventing or degrading progress. A barrier, which may be technological, financial, or behavioral, constrains effective decision-making or functional implementation. As an example, financial problems may mean that a skilled worker cannot be hired in a timely manner.

Systems/software engineering (SSE) and project management $(\mathrm{PM})$ practices have a socio-politicaltechnical nature that doesn't fit well with most of the highly formalized theories of mathematics and science. The latter can be predictive because they are based on well-known universal and timeless assumptions. But SSE and PM involve people and shifting factors that need to be periodically re-oriented and re-evaluated to understand how they affect success [18]. Table 2 identifies some challenges associated with measuring cause and effect.

Table 2. Effect Measurement: Issues and Challenges

\begin{tabular}{|c|}
\hline segative innuence on intangiore \\
\hline $\begin{array}{l}\text { Perceived Severity: Is a proposed action likely to lead to } \\
\text { near-term failure if it is not successful? }\end{array}$ \\
\hline $\begin{array}{l}\text { Perceived Efficacy: What is the likelihood that a } \\
\text { proposed action will achieve the desired objective? }\end{array}$ \\
\hline $\begin{array}{l}\text { Perceived Acceptance: Is there a consensus - implicit or } \\
\text { tacit - for taking proposed actions. }\end{array}$ \\
\hline $\begin{array}{l}\text { Perceived Self-Efficacy: Is a proposed action detrimental } \\
\text { to the decision-maker's position, if taken. }\end{array}$ \\
\hline $\begin{array}{l}\text { Perceived Success Criteria: Is the definition of success } \\
\text { clear and understood by all actors? Is it measurable? Can } \\
\text { it be achieved? An assumption of success usually means } \\
\text { "everything goes right." This measure may also involve } \\
\text { the degree to which a software project meets user } \\
\text { requirements that may not be stable. [19] }\end{array}$ \\
\hline $\begin{array}{l}\text { Perceived Usability: How do users perceive the usability } \\
\text { of delivered tools and their functionality? Tools that are } \\
\text { not easily usable will fall into disuse (as users find } \\
\text { workarounds). }\end{array}$ \\
\hline
\end{tabular}

\subsection{Risk Analysis}

A risk factor is an event that may happen that may cause project failure. Failure is not guaranteed if the event occurs. The severity of the event can affect the likelihood of project failure. Some organizations begin new complex projects without ever having completed a project with similar characteristics - size, technology, complexity, and schedule. Every new project is a learning opportunity but is also an opportunity to fail to apply lessons learned from previous projects.
Paraphrasing Rechtin [20], functionality, cost and schedule cannot be specified independently. At least two of these three must depend on the others. We have suggested some simple metrics as early warning signs which are cost overruns, schedule slippage, labor hour overruns, and lack of functionality in [8]. We chose to separate costs into labor costs and other costs in our model (Figure 1). These factors are proposed as the determinants for potential failure in our model described in section 6 .

At the beginning of the project, project management needs to choose a time unit to calculate changes in these factors. For each of these factors, the delta change at succeeding times may be zero, a constant increase or decrease, or an accelerating increase. Costs will continue to increase as the project continues. Schedule may increase due to slippage. Functionality can increase or decrease for several reasons. Table 3 addresses other challenges associated with risk analysis.

Table 3. Risk Issues

Assessing Risk: Choosing the best metric(s) for risk requires an understanding of the project domain. Risk must be assessed within an understanding of domain concepts and principles.

Experience: Before beginning a project, the organization should have in-house experience in conducting software projects of this type, technology, complexity, and magnitude. Assessing the level of experience is difficult due to the variability of individual's skills.

Assessing complexity: Choosing metrics to measure system/project complexity is difficult because there are few agreed upon ways to assess complexity.

Assessing feasibility: Given a complexity metric, how do we assess feasibility (potential for success)? In terms of cost, schedule, functionality?

Availability: If rightly skilled personnel are not available, can the project be completed by eliminating or replacing the components demanding those skills?

Recovery and Remediation - 1: Does the management team have the right skills to affect a recovery?

Recovery and Remediation - 2: Does the technical team have the right skills to achieve recovery of the project?

Complexity arises from several factors - among them requirements creep and impact on system architecture, amount of attempted functionality delivery, and interdependencies among system components. As complexity increases in a system/project, nonlinear effects are likely to predominate. Modeling non-linearity considering internal and external dependencies can become a complex process in its own right. 
For AAS, both FAA and IBM significantly underestimated the complexity and effort required to design and test the real-time software to implement the different subsystems. FAA did not have adequately trained staff to review IBM's software development efforts. And, FAA did not have adequate metrics to identify problems despite over 2,100 program trouble reports filed by IBM as of March 1994, of which 800 were emergency or mission critical needing immediate resolution. Such resolution was not forthcoming in a timely manner. [7]

\subsection{Cost-Benefit Analysis (CBA)}

Every software project is undertaken to produce some benefit, whether a service or capability. Every project has costs in multiple categories associated with it. A true cost analysis seeks to allocate all costs - both direct and indirect - using monetary equivalents to determine if a project is initially worthwhile doing and, later, if it should be continued. A CBA seeks to monetize the effects and/or achievements of a project in order to compare them to the costs to determine if there is a net positive return-on-investment (ROI). Table 4 presents some challenges in performing CBA.

Table 4. Cost-Benefit Analysis (CBA)

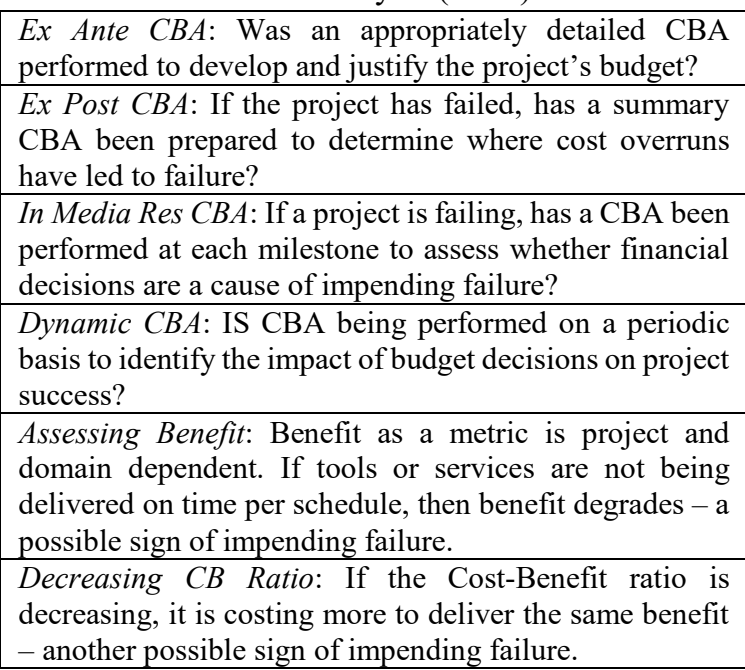

Depending on the success criteria, computing CBA can vary in difficulty. A binary decision might be delivery of tools and/or services per the schedule. CBA then becomes an issue relative to budget - under, on, or over - and by how much. Simple yes, but an effective evaluation. The difficulty of computing CBA increases as the success criteria become more complex.

\subsection{Factor Analysis}

In [8], we proposed a framework for analysis which identified three key factors; Schedule, cost, and functionality (based on previous analysis by Rechtin [20] for system architectures). Each of these factors needs to be assessed. But we must understand that these factors are interdependent and changes in one area may have a nonlinear effect in other areas. These factors are the determinants for potential for failure in our proposed model described in section 6 . The next sections discuss issues for each of these factors.

\subsubsection{Schedule: Issues and Challenges}

As noted, once a schedule has slipped, it is likely to slip further. Rechtin [20] noted the time to complete is proportional to the time spent. Many subfactors can affect a project's schedule. Caper Jones [21] has addressed some of these noting the relationships between higher software quality and shorter development schedules.

Once you fall behind, you cannot catch up. In complex projects with multiple subsystems, slippage in one subsystem has interdependent impacts upon other subsystems. Taken as a whole, overall slippage may be accelerating due to these interdependencies.

Adding more personnel can rarely reduce slippage due to increased team communications - a lesson noted in the Mythical Man Month. Adding more funding affects either labor hours or tools and technology for developing technology. The downside is that there is a delay in acquiring these items and training may be required before their impact affects the schedule. In any event, the best that can be expected is to decrease the rate of schedule slippage.

Table 5 examines a few issues related to schedule.

Table 5. Schedule Issues

\begin{tabular}{|c|}
\hline $\begin{array}{l}\text { Slippage Acceleration: If schedule slippage is } \\
\text { accelerating, are there actions to be taken that can arrest } \\
\text { such acceleration? }\end{array}$ \\
\hline $\begin{array}{l}\text { When is Done? Many projects are never done, unless } \\
\text { obsolescence or lack of funding do them in. Rather, there } \\
\text { are (almost) always new or changing requirements and/or } \\
\text { enhancements that can be made to any system. New or } \\
\text { changed requirements put pressure on the schedule and } \\
\text { may require schedule and cost recalibration. }\end{array}$ \\
\hline $\begin{array}{l}\text { Milestones: These are useful for assessing where you are } \\
\text { and deciding what to do next. Milestones are not } \\
\text { complete if work is unfinished. Marking milestones as } \\
\text { complete, and delivering partial documents or code } \\
\text { segments that cannot support downstream development } \\
\text { work is not how milestones are successfully applied. [21] }\end{array}$ \\
\hline $\begin{array}{l}\text { Falling Less Behind: Are there actions that can be taken } \\
\text { to recover some schedule slippage? }\end{array}$ \\
\hline
\end{tabular}


Forward reallocation of functionality to future milestones may allow some tasks to be performed concurrently. Simplifying functionality may eliminate dependencies that may yield opportunities for concurrent development. Alternatively, cancellation of functionality reduces milestones and deliverables and, perhaps, necessitates rescheduling, but allows a schedule catchup. Doing less, but doing it well may be the solution to recovery [8].

As an example, FAA did not properly perform oversight of complex subsystems which did not reveal lack of progress and, when discovered, required schedule delays to analyze the problems and implement corrective actions [7].

\subsubsection{Cost (funding): Issues and Challenges}

Cost growth can arise due to many factors. Some of these may be beyond the control of the project team; these are exogeneous factors. Recognizing when they occur and adjusting as quickly as possible may make the pain and difficulty bearable.

In government (U.S.), funding is often appropriated on an annual basis, with $\sim$ eighteenmonth projects, but no assurance of allocation. You know how much you ostensibly have for the coming year but are not guaranteed to receive the same amount or an increase in coming years. Knowing this allows you to plan for deltas that may cause slippage in your project and necessitate replanning.

Adhering to a budget is a hard process requiring management stamina. Tracking expenditures requires diligence. Once costs exceed the budget by some percentage, which varies by project, hard decisions need to be made and quickly. Like schedule slippage, you can't recover sunk money, only replan not to get deeper in the red. Rechtin [20] noted that the failure rate of a product is linearly proportional to its cost. Table 6 presents some challenges related to cost.

Table 6. Some Cost Issues

Computing the cost estimate? If you don't have one, how did you prepare a budget? Putting the cart before the horse is a recipe for failure.

Is the funding adequate? If not, what do you give up (relax a constraint - cost, schedule, or functionality)? As Rechtin [20] has noted, you can have two of these, but not all three.

Contingency Funds: Is there a contingency fund for unexpected costs? What percentage of the overall budget is it?

Burn Rate: Is the labor burn rate exceeding that proposed in the project budget? By how much? Is it accelerating? Labor hours need to be tracked by skill category to determine if they indicate problems. Other direct costs also need to be tracked as unanticipated items can arise quickly.

Cost Underruns: If costs in some categories are underrunning the projected burn rate, this might indicate that some work is not being accomplished due to other problems.

As an example, the GAO noted that the implementation plan, including cost and schedule estimates, was overly ambitious given the highly demanding requirements and. the complex software architecture for this system. [7]

\subsubsection{Functionality: Issues and Challenges}

The key tasks of requirements analysis, system design, system development, system testing, and system deployment need to be practiced correctly and reliably no matter which system development methodology is used.

These tasks focus on assuring that the desired functionality is implemented correctly and effectively. From the validation and verification perspective, did the team build the right functionality into the system according to the requirements and is the functionality built right according to accepted design and development principles. Having a system architecture is essential to success. Rechtin [20] observed that form follows function. The system architecture provides the road map to building the system.

Table 7 presents some challenges for functionality.

Table 7. Functionality Challenges

\begin{tabular}{l} 
Following the System Architecture: To slightly misquote \\
that famous American philosopher, Yogi Berra, if you \\
don't know where you are going, no road will get you \\
there. \\
\hline Is the Scope of the Project Feasible? If not, given cost \\
and schedule, what do you give up? The potential \\
problems of software functionality - stakeholder \\
mismatches, gold plating, inflexible solutions, and high \\
risk capabilities - require uncontrolled software projects \\
need stakeholder commitment to system objectives and \\
capabilities. [22] \\
\hline $\begin{array}{l}\text { Getting it Right: Deliver the right functionality at the } \\
\text { milestones. The key is to make it work, then make it work } \\
\text { faster! Or better! Or both! } \\
\text { Performance: Is not an afterthought! Set a performance } \\
\text { budget and try to hit it at each milestone. In the end, } \\
\text { performance substantially affects acceptance even if all } \\
\text { the functionality exists. }\end{array}$ \\
\hline
\end{tabular}

As an example in FAA's AAS Project, the FAA failed to make timely decisions about basic 
requirements (the electronic flight data strips) and complex technology. [7]

\subsection{Technology}

All software projects rely on technology hardware and software - for implementation. Some technologies are well-proven; some are bleeding edge. Failure to assess the feasibility of applying technology - whether selected or mandated - is a critical factor because commitment to a technology may overwhelm considerations of cost and schedule when it does not succeed.

One critical challenge is selecting the right technology. For example, if a component-based software development approach is applied, it is assumed that appropriate off-the-shelf components can be assembled with a well-defined software architecture. Component-based software technologies have advantages, disadvantages, and inherited features that may make excellent or very poor choices for a specific software project. [23] Table 8 presents some technology challenges.

Table 8. Technology: Issues and Challenges

\begin{tabular}{l} 
Maturity: Is the technology proven (used in many \\
projects), but evolving, or relatively new? "Bleeding \\
edge" technology will significantly increase the \\
probability of failure. \\
Quantity: How many different technologies are in use \\
within a software project? Are any of them duplicative \\
and possible candidates for elimination? \\
\hline $\begin{array}{l}\text { Training: Is the development team adequately } \\
\text { (thoroughly) trained in how to use the technology? }\end{array}$ \\
\hline $\begin{array}{l}\text { Re-use: Has the technology been used on a previous } \\
\text { project, which (nearly) succeeded (albeit with some loss } \\
\text { of functionality)? }\end{array}$ \\
\hline $\begin{array}{l}\text { Integration: Are there conflicts between technologies } \\
\text { that preclude their integration in a project? }\end{array}$
\end{tabular}

There is a strong tendency today to rely on open source software (OSS) without understanding how it works if one can understand the API. The premise is that enough "eyeballs on" the software will detect and correct flaws as they emerge through successive evolutions of the software. Three key problems arise with OSS are:

(1) Is the documentation adequate to explain how to use the software properly?

(2) Is the software appropriate for the project, e.g., can it be used without significant adaptation or modification?

(3) Is the software up to date, e.g., has it been improved, renovated, etc.?
We cannot explore these issues in this paper, but they will be some of the critical variables in our Proposed Model for assessing Software Project Failure (Figure 1).

\subsubsection{Tools}

It has been suggested that we use the same tools for forensic analysis that we use for software development. We are not convinced that this is an effective use of these tools because they are oriented towards constructive analysis rather than discovery and diagnostic analysis. We suggest that a new set of tools for diagnostic analysis based on rule-based and logic-based reasoning techniques would provide better analytic capabilities.

A second class of tools is required to build a model of a project and use it determine causes of failure. Current project management tools are focused on maintaining records of a project and the associated housekeeping tasks. Rarely do they perform diagnosis or analysis to detect potential causes of failure. Project management artifacts are diverse, including documents, databases, and automated programs. Even simple tools in this area would be useful in the early stages of forensic analysis.

We suggest a few issues and challenges associated with forensic analysis tools in table 9 .

Table 9. Tools

Discovery Tools: Automated tools are needed to discover the architecture of the software system as-is, the interrelationships between subsystems and modules, and the attributes of these components.

Diagnostic Tools: These tools, containing models of failure in software, would analyze the structure of software systems to identify potential causes of failure (see Root Cause Analysis).

Project Models: Many projects, consciously or not, adhere to a few project architypes. Developing models of projects with flexible syntax will be essential to the development of project discovery tools.

Project Discovery Tools: Like software discovery tools, there is a need for tools to examine and analyze project artifact to build a model for diagnose, analyze, and report. Project Diagnostic Tools: Like software diagnostic tools, there is a need for tools to diagnose, analyze, and report on potential causes of project failure.

Practices are Tools Too: Choosing the right processes and practices can make or break a project. One cannot simply assume that Agile or life cycle processes are appropriate. Processes can focus on specific issues such as security vulnerabilities. For example, specification languages, and security requirements engineering processes may be more or less appropriate for a system with critical security requirements because of the properties of such languages. [24] 
We note that discovery and diagnostic tools will have to be developed for individual programming languages to "recognize and understand" their syntax and semantics. Such tools would also require models of patterns expressible in those languages. The full suite of tools selected needs to provide overlapping, but necessarily reinforcing views of the work in context. Model storming - the practice of using the learning from one model, view, or viewpoint, to update another, is a critical element to avoid or resolve project issues. It is beyond the scope of this paper to enumerate discovery and diagnostic tools and their features and attributes.

\section{Model}

Today, project recovery is becoming a disciplined, focused, collaborative effort. Determining if recovery is possible requires identifying, and measuring the effect of, the causes of the failure and choosing off-setting processes and actions that the available resources may use to facilitate recovery. To this end, we propose an initial model to begin developing a quantitative assessment of the probability of recovery. It is critical to develop a research-based understanding of how the data collected in a forensic analysis can be assembled and used to assess the failure of a project. When the determination is completed, one can realistically decide whether to attempt recovery (with some expectation of success) or cut one's losses.

Our proposed model (Figure 1) projects how data collected during the forensic analysis is related. Our research recommendations describe how this model can be analyzed with data drawn from failed projects. Our model is based on a framework derived from an initial analysis of factors affecting software project failure [8].

The Model is organized into four levels: Sample Variables, Context, Factors, and Outcome.

Sample Variables suggests some of the things that we will measure - either quantitatively or qualitatively - in this research effort. We will identify a set of variables based on a literature search and review. There are both direct costs and indirect costs. Direct costs can be quantitatively assessed. Indirect costs, such as the effect of poor personnel infrastructure on the performance of developer teams will have to be qualitatively assessed. Another variable might be the existence and/or availability of appropriate tools for ongoing assessment of a project.
Context captures the areas of decision-making within a project. Poor decisions are the key to software project failure. [8] Decisions are based on data or lack thereof by personnel associated with the project. But, decision-making uses procedures, rules, heuristics, or "gut instinct" which often can only be qualitatively assessed. Thus, the measured variables must be aggregated into proxy variables that influence the factors.

Factors represent an aggregation of the Context variables into critical elements that will define whether a software project is failing or has failed. As noted in [8], if a software project is behind schedule at a certain point, and continues to fall further behind, the likelihood of recovery according to the original project plan has a decreasing probability. Because the three factors are interdependent, no single equation will generate a definite probability. Rather, we hope to identify a probability range and a set of rules for deciding whether a software project will fail or not.

The probability range and the set of rules will constitute the Outcome of the model.

We recognize the significant difficulties with the advanced techniques that can be used to ascribe causation to the failure of a software project. A recommended research approach would stress the use of converging results from multiple causal analysis methods such as: causal diagrams; flow-graphs (nodes representing project events, with points interconnected a set of linear algebraic equation); statistics; analysis among variables; and causation parameters. [25]

Our methodology and collection techniques for sets of data from multiple projects would address each detected (root cause analysis) cause of failure. We then suggest classification by type, process area, and observed interconnectedness to other causes. Analysis will then be undertaken of type, process area, and interconnectedness. It will be challenging to find cooperating failed projects (organizations do not brag about or publish such data), but we suggest that a sample (size dependent upon research resources) be subjected to these analyses. We believe qualitative analysis will then be possible (and necessary) from a critical assessment of the common denominators for the causal relationships among the processes in the project's areas.

\section{Conclusion}

Our major theme in this paper is that forensic analysis is essential to understanding how and why software projects fail. To achieve that understanding, we must determine the what, when, and where of 
events that led to decisions causing the impending failure. This paper has defined forensic analysis for failing software projects and examined techniques, tools, and methods for determining how and why software projects can fail, and to suggest some mitigating actions to recover from potential failure.

We emphasize that recovery from potential failure does not mean that the project will eventually succeed as envisioned in the original project plan, but that the project will be able to deliver a functional capability within a revised schedule and budget that is some subset of the original project plan. Our conclusions are presented in the following table.

Table 10. Conclusions

\begin{tabular}{|c|}
\hline $\begin{array}{l}\text { Project recovery as an activity is substantially different } \\
\text { from project management but may be thought of as a sub- } \\
\text { discipline. Our research will elucidate the differences as } \\
\text { a basis for future training. }\end{array}$ \\
\hline $\begin{array}{l}\text { Project failures (and substantive data): Data are sparse. } \\
\text { Current analytics lack rigor in the analysis of the } \\
\text { determinants of failure. }\end{array}$ \\
\hline $\begin{array}{l}\text { Project Complexity: The effects of decisions in different } \\
\text { project components and software areas can lead to } \\
\text { nonlinear effects that may result in emergent behavior as } \\
\text { Midha [26] discussed. Software developers can expect } \\
\text { surprises. }\end{array}$ \\
\hline $\begin{array}{l}\text { Research Model: While the proposed model is a start, } \\
\text { future work will refine the number of variables, better } \\
\text { elucidate the context, and develop the relationships } \\
\text { between the three factors }\end{array}$ \\
\hline $\begin{array}{l}\text { Research Techniques: are understood and available, but } \\
\text { infrequently discussed in the literature (wisdom, or } \\
\text { academic). }\end{array}$ \\
\hline $\begin{array}{l}\text { Research Progress has had a questionable (perhaps } \\
\text { limited) impact on reducing project failures and project } \\
\text { success. }\end{array}$ \\
\hline
\end{tabular}

\section{Recommendations}

Our conclusions indicate there is much work to be done in this area to develop practices, standards, and a cadre of trained forensic analysts. We present some recommendations in the following table.

Table 11. Recommendations for Future Research

\begin{tabular}{l} 
A Body of Knowledge (BOK) should be developed for \\
Forensic Analysis of Software Projects. \\
\hline A Forensic Analyst should be an integral part of every \\
major software project. S/he should report to the Project \\
Manager, but also, have a conduit to the sponsors. \\
\hline $\begin{array}{l}\text { Forensic analysis of software projects should be an } \\
\text { integral part of project management and reported in } \\
\text { periodic reviews, including major milestones. }\end{array}$ \\
New Forensic Metrics Development: Jones [27] notes the \\
problem of existing metrics. We suggest the need for \\
new, explicit metrics for forensic analysis. \\
\hline $\begin{array}{l}\text { A Certification Program should be developed to train } \\
\text { forensic analysts according to the Body of Knowledge. }\end{array}$ \\
\hline
\end{tabular}

Academics: To further research in this critical area, an $\mathrm{MS} / \mathrm{Ph} . \mathrm{D}$. program should be developed in Forensic Analysis for Software Projects.

A training program should be developed for software engineers, program managers, and other team members in the basic of forensic analysis.

\section{Acknowledgements}

We thank the reviewers for their cogent suggestions and insights for improving the content and presentation of this paper. We appreciate the comments and suggestions from several of our colleagues on this critical topic.

\section{References}

[1] Lehtinen, T. O., Mäntylä, M. V., Vanhanen, J., Itkonen, J., \& Lassenius, C. (2014). Perceived causes of software project failures-An analysis of their relationships. Information and Software Technology, 56(6), 623-643.

[2] Peisert, S., M. Bishop, S. Karin, and K. Marzullo. 2007. "Toward Models of Forensic Analysis", Proceedings of the Second International Workshop on Systematic Approaches to Digital Forensic Engineering

[3] Charette, R.N. 2005. "Why Software Fails?". IEEE Spectrum, retrieved 10/02/2019 from https://spectrum.ieee.org/computing/software/whysoftware-fails

[4] Jones, C. 2006. "Why Projects Fail?" CrossTalk: The Journal of Defense Software Engineering, 19(6):4-9

[5] Bryson, J.M., and P. Bromiley. 1993. "Critical Factors Affecting the Planning and Implementation of Major Projects", Strategic Management Journal, 14(5):319-337; https://www.jstor.org/stable/2486820

[6] Krigsman, M. 2012. "Worldwide cost of IT failure (revisited): \$3 trillion” ZD Net, April 10, 2012.

[7] U.S. Government Accountability Office (GAO). 1994. Advanced Automation System: Implications of Problems and Challenges, https://www.gao.gov/products/T-RCED94-188

[8] Cohen, S.M., S.H. Kaisler, \& W.H. Money. 2020. Forensic Analysis of Failed Software Projects, HICSS-53 Tutorial, Maui, HI, January 7, 2020.

[9] Gardner, D. J. (2000). How to avoid IT project failures. Consulting to Management, 11(1), 21.

[10] Pardo, T. A., \& Scholl, H. J. J. 2002. Walking atop the cliffs: Avoiding failure and reducing risk in large scale egovernment projects. 35th annual Hawaii International Conference on System Sciences (pp. 1656-1665). IEEE, January.

[11] Shahid, M., \& Tasneem, K. A. (2017). Impact of avoiding non-functional requirements in software development stage. American Journal of Information Science and Computer Engineering, 3(4), 52-55.

[12] Lova, A., Maroto, C., \& Tormos, P. (2000). A multicriteria heuristic method to improve resource allocation 
in multiproject scheduling. European Journal of Operational Research, 127(2), 408-424.

[13] Williams, T., C. Eden. F. Ackerman et al. 2001. "The Use of Project Post-Mortems", Project Management Institute Annual Symposium.

[14] Gammage, M. 2011. Why Your IT Project May Be Riskier Than You Think. Harvard Business Review, 89(11), 22-22.

[15] Krush, Alesia, 2018. "Why 50\% of IT Projects Fail, and How to Not Let that Happen to You." https://www.objectstyle.com/agile/software-projectsfailure-statistics-and-reasons, Feb 14.

[16] Smale, T. 2019. "Why Software Projects Fail, and the Traps You Can Avoid That Could Spell Disaster," https://www.entrepreneur.com/article/329019.

[17] Boehm, B. and A. Jain. 2014. "The Value-Based Theory of System Engineering: Identifying and Explaining Dependencies", INCOSE International Symposium

[18] Dwivedi, Y. K., Ravichandran, K., Williams, M. D., Miller, S., Lal, B., Antony, G. V., \& Kartik, M. (2013, June). IS/IT project failures: a review of the extant literature for deriving a taxonomy of failure factors. In International Working Conference on Transfer and Diffusion of IT (pp. 73-88). Springer, Berlin, Heidelberg.

[19] Nurmuliani, N., Zowghi, D., \& Powell, S. (2004, April). Analysis of requirements volatility during software development life cycle. In 2004 Australian Software Engineering Conference. Proceedings. (pp. 28-37). IEEE.

[20] Rechtin, E. 1991. Systems Architecting: Creating and Building Complex Systems, CRC Press, PrenticeHall, Englewood Cliffs, NJ.
[21] Jones, C. 2004. Software project management practices: Failure versus success. CrossTalk: The Journal of Defense Software Engineering, 17(10), 5-9.

[21\} Boehm, B. 1996. Anchoring the software process. IEEE software, 13(4), 73-82.

[22] Cai, X., Lyu, M. R., Wong, K. F., \& Ko, R. 2000, Component-based software engineering: technologies, development frameworks, and quality assurance schemes. In Proceedings Seventh Asia-Pacific Software Engineering Conference. APSEC 2000 (pp. 372-379). IEEE., December [23] Khan, M. U. A., \& Zulkernine, M. 2009. On selecting appropriate development processes and requirements engineering methods for secure software. 33rd Annual IEEE International Computer Software and Applications Conference, 2:353-358. IEEE. , July

[24] Heise, D. R. (1975). Causal analysis. John Wiley \& Sons.

[25] Midha, V. 2008. Does complexity matter? The impact of change in structural complexity on software maintenance and new developers' contributions in open source software. ICIS 2008 Proceedings, 37.

[26] Jones, C., \& CTO, N. 2017. The mess of software metrics.

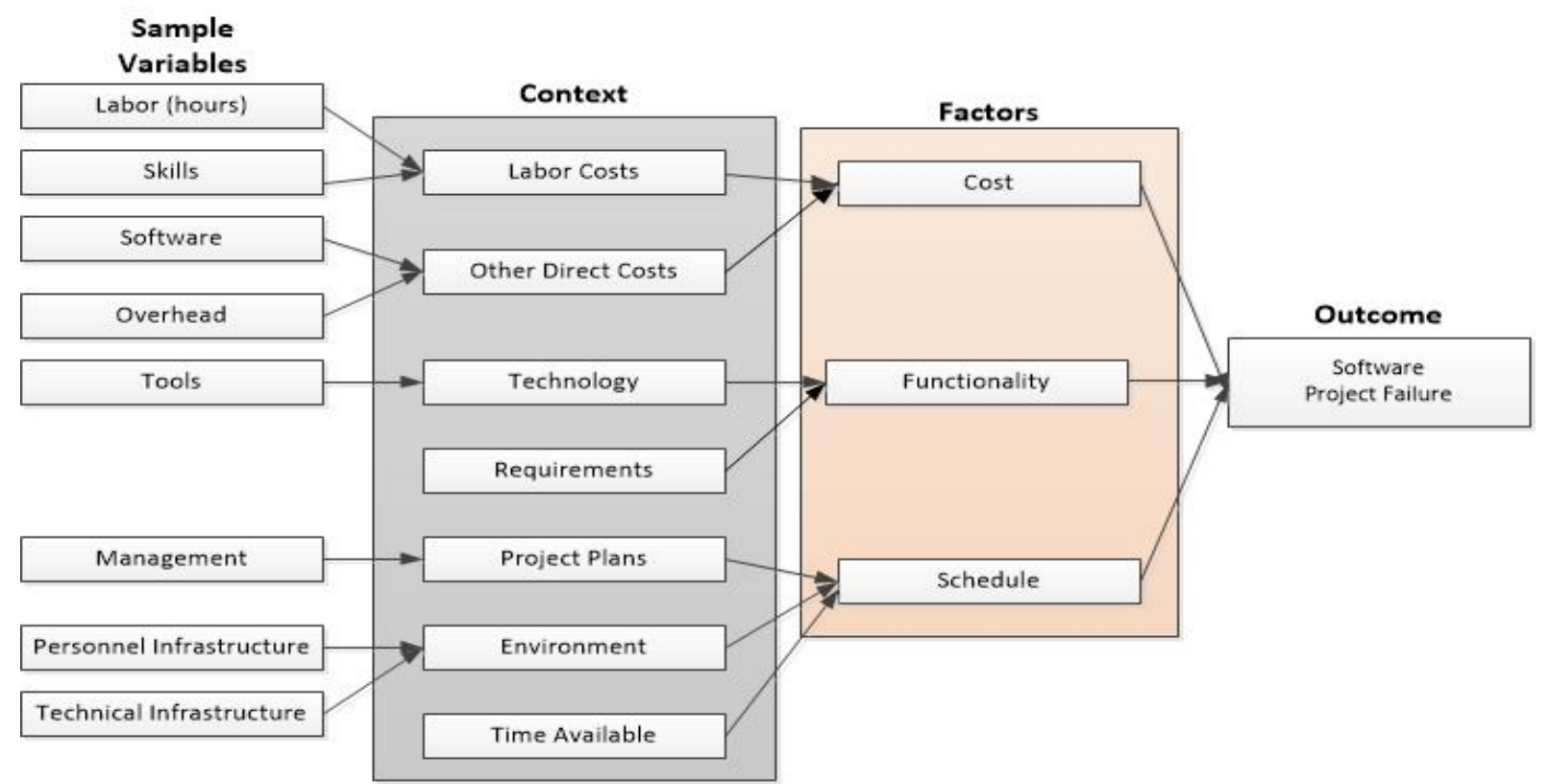

Figure 1. Proposed Model for Assessing Software Project Failure. 